\title{
Correction to: Exploration of photoreduction ability of reduced graphene oxide-cadmium sulphide heteronanostructures and their intensified activities against harmful microbes
}

Sanjukta Ghosh ${ }^{1}$, Piu Das ${ }^{1}$, Bapan Bairy ${ }^{1}$, Raktim Ghosh², Somasri Dam², and Moni Baskey Sen ${ }^{1, *}$ (D)

${ }^{1}$ Materials Research Laboratory, Department of Chemistry, The University of Burdwan, Golapbag, Burdwan, West Bengal 713104, India

${ }^{2}$ Department of Microbiology, The University of Burdwan, Burdwan, West Bengal 713104, India

Published online:

17 August 2021

(C) Springer Science+Business Media, LLC, part of Springer Nature 2021
Correction to:

J Mater Sci

https://doi.org/10.1007/s10853-021-06349-4

The original article has been revised to correct an error in the author affiliations.
Publisher's Note Springer Nature remains neutral with regard to jurisdictional claims in published maps and institutional affiliations.

The original article can be found online at https:/ / doi.org/10.1007/s10853-021-06349-4.

Address correspondence to E-mail: moni.baskey@gmail.com 